\title{
Entrevista a Isabel Ortiz y Matthew Cummins
}

\author{
29 de enero de 2021
}

Revista Derechos en Acción ISSN 2525-1678/ e-ISSN 2525-1686

Año 6/No 18, Verano 2020-2021 (21 diciembre a 20 marzo), 846-855

DOl: https://doi.org/10.24215/25251678e499

Isabel Ortiz es doctora en economía por la London School of Economics. Es directora del Programa sobre Justicia Social Global de la Iniciativa para el Dialogo de la Universidad de Columbia, Nueva York (EEUU); y ex directora de la Organización Internacional del Trabajo y de UNICEF. Entre 2013 y 2019 fue Directora del Departamento de Protección Social de la Organización Internacional del

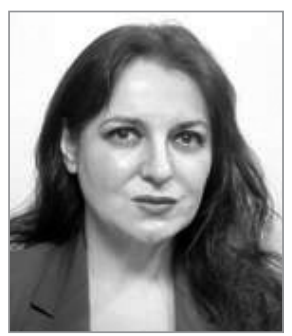
Trabajo (OIT) de las Naciones Unidas. Anteriormente, fue Directora Asociada de Política y Estrategia de UNICEF (2009-2012) y Asesora Superior en el Departamento de Asuntos Económicos y Sociales de las Naciones Unidas (2005-2009). De 1995 a 2003 fue economista de proyectos y funcionaria superior del Banco Asiático de Desarrollo (BAD), donde fue miembro fundador de su Unidad de Reducción de la Pobreza.

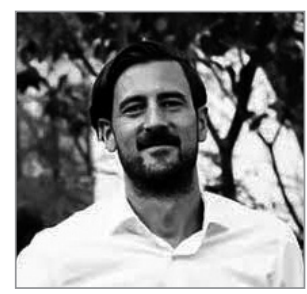

Matthew Cummins es un economista que ha trabajado en el Programa de las Naciones Unidas para el Desarrollo, UNICEF y el Banco Mundial. Cummins trabaja como economista principal en UNICEF, donde dirige los portfolios de finanzas públicas y protección social en África oriental y meridional. Antes trabajó con el PNUD, el Banco Mundial y con el Cuerpo de Paz. Ha escrito más de 50 publicaciones y tiene una maestría en economía internacional de Johns Hopkins SAIS. 
-Ustedes han estudiado las medidas de ajuste y austeridad implementadas en todo el mundo. ¿Podría resumir en qué áreas se han concentrado esas medidas, y cuándo y dónde se han implementado en la última década?

-Desde 2010, la mayoría de los países del mundo han estado implementando políticas fiscales destinadas a reducir el gasto, con un énfasis limitado en aumentar los ingresos. Este enfoque, comúnmente conocido como austeridad, minimiza las políticas públicas y el rol del Estado en la sociedad, generando un verdadero problema para el avance de los derechos humanos. Para el año 2020 los recortes de austeridad se habían convertido en una "nueva normalidad", afectando a 5500 millones de personas o al $72 \%$ de la población mundial — tres de cada cuatro personas-.

Sin embargo, no tiene por qué ser así; hay alternativas, podemos hablar de eso después. Volviendo a su pregunta, los últimos informes ${ }^{1}$ que realizamos en la Universidad de Columbia y la Organización Internacional del Trabajo muestran cómo las medidas de austeridad se extendieron a la mayoría de los países del mundo, a 113 países antes de la pandemia. Un número alarmante de gobiernos adoptaron recortes excesivos del gasto público, asesorados por el FMI; algunos redujeron el gasto por debajo de los niveles previos a la crisis financiera del 2007-08, incluidos muchos países con grandes necesidades de desarrollo humano como Angola, Bután, Burundi, Djibuti, Egipto, Eritrea, Eswatini, Guyana, Honduras, Irán, Irak, Jamaica, Jordania, Líbano, Liberia, Malawi, Mauritania, Moldavia, Nigeria, la República del Congo, Sudán, Túnez, Tuvalu, Yemen... Los países en desarrollo tienen grandes necesidades de inversión

\footnotetext{
1 Isabel Ortiz y Matthew Cummins, Austerity: The New Normal. A Renewed Washington Consensus 2010-24, (Nueva York, Bruselas y Londres: Initiative for Policy Dialogue, International Trade Union Confederation, Eurodad, Services International, Bretton Woods Project) (2019); e Isabel Ortiz, Matthew Cummins, Jeronim Capaldo y Kalaivani Karunanethy, The Decade of Adjustment: A Review of Austerity Trends 2010-2020 in 187 Countries, Ginebra y Nueva York: International Labour Organization, the South Centre and Initiative for Policy Dialogue, Columbia University (2015).
} 
pública en todos los sectores, y especialmente en educación, salud, protección social, vivienda, agua y saneamiento, y deberían ampliar sus presupuestos nacionales, no recortarlos.

- ¿Cuáles han sido los efectos de esos recortes del presupuesto público sobre la igualdad y los derechos económicos y sociales de las mayorías de las poblaciones?

- Los efectos han sido negativos, los recortes han sido fundamentalmente en áreas importantes para el desarrollo social. ¿Cuáles? Para responder a esta pregunta revisamos 779 informes de países del FMI publicados entre 2010 y 2019. Los informes muestran que los gobiernos de todo el mundo consideraron seis políticas principales para consolidar los presupuestos y solo dos medidas para incrementar el presupuesto. Estas son:

Primero, recortes o topes al funcionariado público en 103 países, reduciendo o congelando los salarios y el número de trabajadores del sector público que prestan servicios esenciales a la población, como los profesores, los trabajadores en servicios de salud y sociales, lo que afecta negativamente la prestación de servicios públicos, algo que hemos denunciado en UNICEF desde hace muchos años.

Segundo, reducir o eliminar los subsidios (alimentos, agricultura, combustibles) en 102 países, a pesar de períodos de altos precios de los alimentos y la energía. Cuando se retiran los subsidios básicos, los costos de los alimentos y del transporte aumentan y suelen volverse inasequibles para muchos hogares; los precios más altos de la energía también tienden a contraer actividades económicas que generan empleo. Normalmente se recomiendan safety nets (transferencias para los más pobres), pero estas son insuficientes, no cubren a muchos trabajadores ni a la clase media, que suelen tener ingresos bajos en los países en desarrollo y se ven muy afectados por la subida de precios.

Tercero, reformas de pensiones y de la seguridad social en 86 países, recortando beneficios y deteriorando los sistemas públicos. Reformas típicas incluyen el aumento de las 
tasas de cotización, el aumento de los períodos de elegibilidad, la extensión de la edad de jubilación y/o la reducción de las prestaciones, a veces reformas estructurales que avanzan hacia sistemas privados, a pesar del fracaso de la privatización de las pensiones en décadas anteriores. ${ }^{2}$ Muchas de estas reformas son además contra los estándares internacionales y la legislación nacional. Como resultado, tanto la OCDE como la Organización Internacional del Trabajo proyectan que los futuros pensionistas recibirán beneficios más bajos.

Cuarto, racionalización y focalización de la asistencia social (safety nets) en 84 países, a menudo mediante la revisión de los criterios de elegibilidad y la focalización en los más pobres, lo cual implica una reducción de la cobertura de protección social. Como habíamos señalado antes, las llamadas clases medias y trabajadoras tienen ingresos muy bajos en los países en desarrollo y la focalización en los pobres aumenta su vulnerabilidad. En lugar de focalizar más y reducir la asistencia social para gastar menos, se deben construir sistemas de seguridad social o protección social inclusivos que respondan a todos los ciudadanos.

Quinto, reformas de flexibilización laboral en 81 países, como la revisión a la baja de los salarios mínimos, la limitación de los ajustes salariales al nivel de costo de vida, la descentralización de la negociación colectiva y el aumento de la capacidad de las empresas para despedir empleados. En un contexto de desaceleración económica — como en Argentina- estas reformas generan una "precarización" del mercado laboral y deprimen los ingresos de los trabajadores.

Sexto, reformar los sistemas de salud en 44 países, incluido el aumento de tarifas y copagos para los pacientes, así como la introducción de medidas de ahorro de costos en los centros

\footnotetext{
2 Ver entre otros Organización Internacional del Trabajo, Informe Mundial sobre la Proteccion Social 2017-19 (Ginebra: OIT) (2017); Isabel Ortiz, Fabio Durán, Stefan Urban, Veronika Wodsak y Zhiming Yu, La reversión de la privatización de las pensiones: Reconstruyendo los sistemas públicos de pensiones en los países de Europa Oriental y América Latina, 2000-2018 (Ginebra: OIT) (2019).
} 
públicos de salud. Y así, en 2020, COVID-19 tuvo un impacto devastador en los países. El débil estado de los sistemas de salud pública, sobrecargados, con fondos insuficientes y sin personal, debido a la década anterior de austeridad, había dejado a los países propensos a fallas en la atención médica, con efectos catastróficos para las poblaciones.

Séptimo, después de los recortes, las medidas más comunes para aumentar el presupuesto son los impuestos al consumo o el IVA sobre bienes y servicios básicos en 100 países. Esta medida contrae la actividad económica y es regresiva (es decir, los hogares más pobres pagan una proporción significativamente mayor de sus ingresos), así pues, también con impactos sociales negativos.

Octavo, privatizaciones en 59 países y fortalecimiento de asociaciones público-privadas (APP) en 60 países. La privatización genera ingresos a corto plazo, pero también pérdidas a largo plazo dada la falta de ingresos futuros. Los riesgos adicionales de privatización incluyen despidos, aumentos de tarifas y bienes y servicios básicos inasequibles o de baja calidad. Con respecto a las APP, a menudo se promueven como una solución para países con restricciones fiscales, pero a menudo dan como resultado tarifas más altas y una peor calidad de los servicios.

Las políticas de austeridad han infligido graves daños a la población de los países donde se ha aplicado. Las mujeres han sido particularmente afectadas. La desigualdad creció enormemente en la última década, generando más ricos y más pobres. Millones de personas se vieron empujadas a la pobreza por la crisis del empleo y por los recortes de austeridad -y esto fue antes de la pandemia-.

\section{-Al mirar para atrás y ver la amplitud y continuidad de las medidas de austeridad en la última década le preguntamos ¿hay sectores de la sociedad a quiénes no se les ha exigido ser austeros y que hagan sacrificios como la mayoría?}

-Sí, muy injusto. En perspectiva, las decisiones macroeconómicas y fiscales tomadas por la mayoría de los gobiernos durante 
la última década 2010-20 son alarmantes. Para responder a la crisis financiera global en 2008-09, se asignaron 10 billones de dólares al sector financiero y solo 0,24 billones de dólares en ayuda a los países en desarrollo. Lo que se hizo fue asignar al FMI otros 0,75 billones de dólares, más del triple de la ayuda al desarrollo, una institución que no mira (o solo mira superficialmente) los impactos sociales de las reformas que propone. Y mientras se entregaron 10 billones de dólares para rescatar al sector financiero en los países de la OCDE y del G20, los costos del ajuste recayeron sobre la población.

-En un artículo publicado en The Lancet en el mes de abril de 2020, junto a otras/os autoras/es advertían que el FMI y el Banco Mundial estaban desplegando músculos institucionales e instrumentos financieros que nos alertaban acerca de la continuidad de las políticas ortodoxas aún durante la pandemia. ¿Ve que hoy el FMI y el Banco Mundial efectivamente impulsan una agenda de ajuste, austeridad y mercantilización de servicios? En ese caso, ¿en qué áreas se están concentrando esas políticas?

-Los gobiernos han adoptado medidas extraordinarias para hacer frente a la pandemia de coronavirus, tales como confinamientos, la expansión de los servicios de salud pública de emergencia y de planes de estímulo fiscal y protección social para proteger a las personas y los empleos. Si bien el FMI ha apoyado a muchos países con financiación urgente, esto ha provocado un aumento de la deuda y de los déficits fiscales. Esto señala el comienzo de una nueva ola de austeridad.

Según los informes nacionales del FMI para 80 países en desarrollo, analizados por Eurodad, muestran que se prevé que 72 países comiencen procesos de austeridad o consolidación fiscal en 2021, con el fin de cumplir con el servicio de la deuda. ${ }^{3}$

3 Ver Eurodad, Arrested Development: International Monetary Fund lending and austerity post Covid-19 (Brussels: Eurodad) (2020); y Oxfam IMF paves way for new era of austerity postCOVID-19 (Nairobi: Oxfam) (2020). 
Se espera que los gobiernos implementen medidas de austeridad de un promedio del 3,8 \% del PIB, y más de la mitad de este ajuste (alrededor del $2 \%$ del PIB) se llevará a cabo en 2021, a pesar de que la pobreza ha incrementado en todo el mundo por la pandemia y las necesidades sociales son más altas. El Banco Mundial estima que 150 millones de personas más habrán caído en la pobreza extrema para 2021.

Como en la década anterior de ajuste, estas medidas afectarán de manera desproporcionada a la población: de nuevo se imponen impuestos al consumo para la mayoría de los países. Se espera que los países, incluidos Barbados, El Salvador, Lesoto y Túnez, congelen o reduzcan los salarios y empleos del sector público, lo que podría significar servicios de menor calidad y menos profesores, médicos y asistentes sociales en países que tienen muchas necesidades sociales.

-El FMI incentiva a la inversión pública en contexto de COVID-19 en sus investigaciones académicas y a nivel discursivo de sus máximas autoridades, pero sus órganos decisores y técnicos recomiendan y elogian en un número de países políticas de recortes de gasto y flexibilización laboral en América Latina. ¿A qué se debe esta discordancia?

- Siempre ha habido una gran divergencia entre lo que dicen los Departamentos de Relaciones Públicas y de Investigación del FMI, y lo que realmente hacen los economistas del FMI en los países. La realidad está en lo que se hace, en las operaciones del día a día del FMI en los países que afectan las políticas públicas para billones de personas. No hay que confundirse por lo que se diga de cara al público o en unos artículos de investigación abstractos.

- ¿Es posible sostener el ritmo de expansión del gasto si el acceso al mercado de crédito está limitado por el deterioro de la sostenibilidad de las deudas soberanas a nivel global? ¿Qué recursos pueden y deberían movilizar los países del Sur Global en el contexto actual? 
- Las medidas de austeridad se están utilizando como un caballo de Troya para reducir las políticas públicas, argumentando que los derechos humanos y muchas políticas de desarrollo no son asequibles, y que los recortes del gasto público son inevitables. Esto simplemente no es cierto; hay alternativas, incluso en los países más pobres. Existe una amplia variedad de opciones para ampliar el espacio fiscal y generar recursos financieros.

Las siguientes ocho opciones de financiamiento están respaldadas por la ONU (ver, por ejemplo, OIT, UNICEF y ONU MUJERES $)^{4}$ así como por las IFI. Muchos gobiernos los han estado aplicando durante décadas, mostrando una amplia variedad de opciones. Las ocho opciones son:

1. Aumento de los ingresos tributarios: los impuestos son el canal principal para generar recursos, lo cual se logra modificando las tasas impositivas, por ejemplo, sobre las ganancias corporativas, actividades financieras, propiedad, importaciones/ exportaciones, recursos naturales o fortaleciendo la recaudación de impuestos. Dados los niveles crecientes de desigualdad, es importante adoptar impuestos progresivos, tributación a los que tienen más ingresos; los impuestos al consumo deben evitarse pues generalmente son regresivos y contrarios al progreso social. Muchos gobiernos están aumentando los impuestos para logar mayor inversión social. Por ejemplo, Bolivia, Mongolia y Zambia están financiando pensiones universales y prestaciones infantiles con impuestos a la minería y el gas; Ghana, Liberia y Maldivas han introducido impuestos sobre el turismo para apoyar programas sociales; y Brasil introdujo un impuesto sobre las transacciones financieras para expandir la protección social. Los impuestos sobre la riqueza se están proponiendo como la mejor política para hacer frente a la pandemia de COVID-19.

4 Isabel Ortiz; Matthew Cummins; Jeronim Capaldo \& Kalaivani Karunanethy, Espacio fiscal para la protección social y los Objetivos de Desarrollo Sostenibles: Alternativas para ampliar la inversión social en 187 países (Ginebra: OIT) (2017). 
2. Eliminación de los flujos financieros ilícitos: se estiman en más de diez veces el tamaño de toda la ayuda al desarrollo, una cantidad titánica de recursos se escapa ilegalmente de los países en desarrollo cada año. Los gobiernos deberían dedicar más atención a combatir el lavado de dinero, la evasión fiscal, la facturación comercial errónea y otros delitos financieros que son ilegales y privan a los gobiernos de los ingresos necesarios para el desarrollo social.

3. Ampliar la cobertura de la seguridad social: para la protección social, aumentar la cobertura y, por lo tanto, la recaudación de las contribuciones al seguro social es una forma sostenible de financiar la protección social, liberando espacio fiscal para otros gastos sociales. Las prestaciones de protección social vinculadas a las cotizaciones basadas en el empleo también fomentan la formalización de la economía informal; ejemplos notables son el Monotributo de Uruguay o SIMPLES en Brasil. Argentina, Túnez y muchos otros han demostrado la posibilidad de ampliar tanto la cobertura como las contribuciones formalizando y protegiendo a los trabajadores de la economía informal.

4. Reestructuración de la deuda existente: los países con un alto nivel de sobreendeudamiento deben considerar la reestructuración si la legitimidad de la deuda es cuestionable y/o el costo de oportunidad en términos de empeoramiento de la población es alto. En los últimos años, más de 60 países han renegociado exitosamente sus deudas, y más de 20 han repudiado la deuda pública, como Ecuador, Islandia e Irak, que invirtieron los ahorros del servicio de la deuda en programas sociales.

5. Reasignación del gasto público: este es el enfoque más ortodoxo, si se hace, debe ser reemplazando las inversiones de alto costo y bajo impacto por aquellas con mayores impactos sociales, eliminando ineficiencias en el gasto y/o combatiendo la corrupción. Por ejemplo, Costa Rica y Tailandia reasignaron el gasto militar para financiar servicios de salud universales. 
6. Uso de las reservas de divisas del banco central y reservas fiscales: esto incluye la extracción de ahorros fiscales y otros ingresos estatales almacenados en fondos especiales, como fondos soberanos, y/o el uso de reservas de divisas en exceso en el banco central para el desarrollo nacional y regional.

7. Ayuda al desarrollo y transferencias: aumentar las transferencias Norte-Sur o Sur-Sur. Las transferencias bilaterales y regionales pueden impulsar las inversiones sociales y merecen atención.

8. Adopción de un marco macroeconómico más flexible: implica tener una mayor tolerancia a la inflación o al déficit fiscal, sin poner en peligro la estabilidad macroeconómica.

Cada país es único y todas estas opciones deben examinarse cuidadosamente, incluidos los posibles riesgos, y deben ser discutidas en un diálogo público nacional. Las opciones de financiación no deben decidirse a puerta cerrada por unos tecnócratas en el Ministerio de Finanzas, pues impactan la vida de todos los ciudadanos. El diálogo nacional público entre gobiernos, trabajadores, empleadores, sociedad civil, parlamentos y otros actores es fundamental para generar voluntad política $\mathrm{y}$ aprovechar todas las opciones posibles de financiamiento y así evitar la austeridad.

\section{-Usted sostiene que la austeridad no debe ser la "nueva normalidad". ¿Qué políticas deberían entonces recomendar el FMI y otras IFI en este contexto?}

-Financiar los derechos humanos y el desarrollo social es posible. Dada la importancia del gasto público para el desarrollo nacional, es imperativo que las IFI y los gobiernos abandonen la austeridad y otras políticas que benefician solo a unos pocos (los más ricos) y, en cambio, exploren todas las alternativas posibles de financiamiento explicadas antes para garantizar el empleo con protección social, el crecimiento inclusivo y sostenible, las inversiones sociales y ecológicas, e implementar los derechos humanos. 